\title{
Review
}

Complications

Diabetes Metab J 2020;44:372-381

https://doi.org/10.4093/dmj.2020.0138

pISSN 2233-6079 · eISSN 2233-6087

DIABET\&S \& METABOLISM JOURNAL

\section{Coronavirus Disease 2019 and Diabetes: The Epidemic and the Korean Diabetes Association Perspective}

\author{
Junghyun Noh ${ }^{1}$, Hyun-Ha Chang ${ }^{2}$, In-Kyung Jeong ${ }^{3}$, Kun Ho Yoon ${ }^{4}$ \\ ${ }^{1}$ Division of Endocrinology and Metabolism, Department of Internal Medicine, Inje University Ilsan Paik Hospital, Goyang, \\ ${ }^{2}$ Division of Infectious Diseases, Department of Internal Medicine, School of Medicine, Kyungpook National University, Daegu, \\ ${ }^{3}$ Department of Endocrinology and Metabolism, Kyung Hee University Hospital at Gangdong, Kyung Hee University School of Medicine, Seoul, \\ ${ }^{4}$ Division of Endocrinology and Metabolism, Department of Internal Medicine, College of Medicine, The Catholic University of Korea, Seoul, Korea
}

Diabetes has been associated with more severe outcomes and higher mortality in coronavirus disease 2019 (COVID-19) patients compare to morbidity and mortality in patients without diabetes. Several mechanisms may play a role in this greater morbidity and mortality, especially uncontrolled hyperglycemia, an impaired immune system, pre-existing proinflammatory states, multiple comorbidities, and dysregulated angiotensin-converting enzyme 2 signaling. Thus, the diabetes medical community emergently needs to know about COVID-19 and its effects on patients with diabetes, as they must take precautions to carefully manage these patients during the COVID-19 pandemic. The Korean Diabetes Association provides some guidance and practical recommendations for the management of diabetes during the pandemic. This report provides insight into the association between diabetes and COVID-19, proper management of diabetes in patients with COVID-19 and an official suggestion by the Korean Diabetes Association for managing the COVID-19 outbreak.

Keywords: COVID-19; Diabetes mellitus; Severe acute respiratory syndrome coronavirus 2

\section{INTRODUCTION}

After clusters of pneumonia caused by severe acute respiratory syndrome coronavirus-2 (SARS-CoV-2) emerged in Wuhan, China in early December, 2019, and then rapid spreading of SARS-CoV-2 was occurred throughout the globe at present. As of June 12, 2020, 7,273,958 confirmed cases, including 413,372 deaths, have been reported across 216 countries [1]. After a huge outbreak occurred on February 20, 2020, as a result of a super-spreading event within a religious group, in Daegu in southern South Korea, 12,003 confirmed cases and 277 deaths have been reported in South Korea as of June 12, 2020 [2]. Al- though the fatality rate of coronavirus disease 2019 (COVID-19) is lower than that of severe acute respiratory syndrome caused by severe acute respiratory syndrome coronavirus-1 (SARS-CoV-1) and Middle East respiratory syndrome (MERS) caused by Middle East respiratory syndrome-related coronavirus (MERS-CoV), the absolute number of fatalities as a result of COVID-19 is extremely high because of the high prevalence of COVID-19 [3]. The severity of disease varies from asymptomatic infection, to mild self-limiting upper respiratory tract illness to severe pneumonia with respiratory failure, multi-organ dysfunction, and death. Although a large majority of cases are mild, some are severe and fatal.
Corresponding authors: In-Kyung Jeong (1D https://orcid.org/0000-0001-7857-546X Department of Endocrinology and Metabolism, Kyung Hee University Hospital at Gangdong, Kyung Hee University School of Medicine, 892 Dongnam-ro, Gangdong-gu, Seoul 05278, Korea

E-mail: jik1016@khu.ac.kr

Kun Ho Yoon (10) https://orcid.org/0000-0002-9109-2208

Division of Endocrinology and Metabolism, Department of Internal Medicine, College of Medicine, The Catholic University of Korea, 222 Banpo-daero, Seocho-gu, Seoul

06591, Korea

E-mail: yoonk@catholic.ac.kr

Received: Jun. 18, 2020; Accepted: Jun. 23, 2020
This is an Open Access article distributed under the terms of the Creative Commons Attribution Non-Commercial License (https://creativecommons.org/licenses/by-nc/4.0/) which permits unrestricted non-commercial use, distribution, and reproduction in any medium, provided the original work is properly cited. 
Many people with COVID-19 have comorbidities such as diabetes, cardiovascular disease, and hypertension [4-6]. Diabetic patients have been strongly suggested to have more severe outcomes and higher mortality due to COVID-19 than those without diabetes [7]. Thus, the diabetic community urgently needs to know about COVID-19 and its effects on patients with diabetes, and special precautions should be taken in their management during the COVID-19 pandemic. This report aims to describe the association between diabetes and COVID-19, and provides the official suggestions of the Korean Diabetes Association (KDA) for the COVID-19 outbreak.

\section{ASSOCIATION BETWEEN DIABETES AND COVID-19}

People with diabetes are at an increased risk of serious infection [8]. Diabetes was identified as a major contributor to disease severity and fatality in H1N1 (pandemic influenza virus) infection and MERS $[9,10]$.

Currently, most available data come from hospitalized cohorts with a reported prevalence of diabetes in COVID-19 ranging from $5.3 \%$ to $26.4 \%$ worldwide [5,11-19]. A small number of nationwide studies are available. A recent population-based cohort study using the Korean Health Insurance Review and Assessment Service (HIRA) data, among 5,307 COVID-19 patients, 770 (14.5\%) had diabetes in Korea (unpublished data). Data from studies across China estimated the population prevalence of diabetes in COVID-19 patients to be approximately $5.3 \%$ to $11 \%$, which is not higher than the prevalence of diabetes in the general population $[7,20]$. According to the report from the Centers for Disease Control and Prevention (CDC) of United States, 10.9\% of COVID-19 patients have diabetes [21]. To summarize these reports, diabetes is one of the most common comorbidities of COVID-19 infection. It is still unclear whether people with diabetes are more susceptible to COVID-19 infection.

The disease severity and mortality in patients with diabetes were higher than those in patients without diabetes among those with COVID-19 in several studies. A two-center retrospective study performed at hospitals in Wuhan showed a higher proportion of intensive care unit (ICU) admissions ( $17.6 \%$ vs. $7.8 \%, P=0.01)$ and more fatal cases $(20.3 \%$ vs. $10.5 \%, P=0.017$ ) were identified in COVID-19 patients with diabetes than in sex- and age-matched patients without diabetes [22]. Another retrospective, multi-center study of 7,337 cases of COVID-19 in China found, subjects with type 2 diabetes mellitus required more medical interventions and had a significantly higher mortality (7.8\% vs. $2.7 \%$; adjusted hazard ratio [HR], 1.49) than non-diabetic individuals [23]. In a single-center study conducted in Korea, mortality was significantly higher in patients with diabetes (17.2\%) than in those without diabetes (1.2\%) [19]. A study based on the nationwide surveillance data, among 63 fatal cases of COVID-19, 36.5\% were found to have diabetes in Korea [6]. According to a nationwide population-based cohort study conducted in Korea, the prevalence of diabetes among COVID-19 patients who were hospitalized, received oxygen supply, applied mechanical ventilator, and who died were $14.7 \%, 28.1 \%, 41.3 \%$, and $44.6 \%$ respectively (unpublished data). A meta-analysis of 6,452 patients from 30 studies also showed that diabetes was associated with composite poor outcomes including mortality, severe COVID-19, acute respiratory distress syndrome (ARDS), need for ICU care, and disease progression (risk ratio, 2.38 [1.88 to 3.03], $P<0.001 ; I^{2}=62 \%$ ) [7]. These results suggest an association between diabetes and poor prognosis and increased mortality of COVID-19. Publications that have investigated the association between diabetes and severity in patients with COVID-19 are shown Fig. 1.

\section{POTENTIAL MECHANISMS OF LINKING BETWEEN DIABETES AND COVID-19}

There are several suggested mechanisms that might play a role in an association between diabetes and COVID-19 (Fig. 2). Uncontrolled hyperglycemia was reported as a significant predictor of severity and fatality of different viral diseases, including SARS-CoV, 2009 pandemic influenza, and 2012 MERS$\mathrm{CoV}$ infection $[9,10]$. In an observational study conducted in France, long-term glycemic control as assessed using glycosylated hemoglobin (HbAlc) was not associated with COVID-19 severity [24]. Although admission plasma glucose was significantly associated with the primary outcome (tracheal intubation for mechanical ventilation and death within 7 days of admission) in age and sex-adjusted nonlinear models, it was not a predictor of the severity of COVID 19 in multivariable models [24]. HbA1c was also not a predictor of COVID 19 severity in a single center study in Korea [19]. A retrospective multicenter study conducted in China showed that well-controlled blood glucose as assessed using glycemic variability was associated with markedly lower mortality than in individuals with 


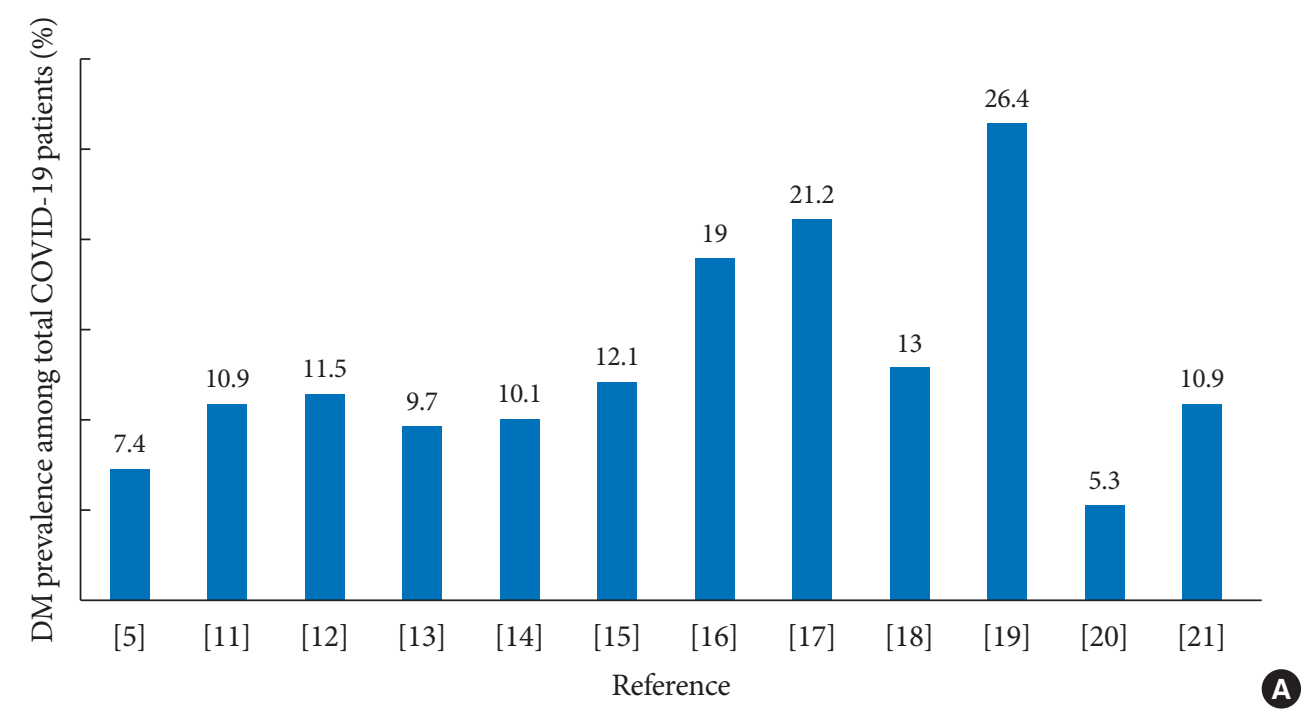

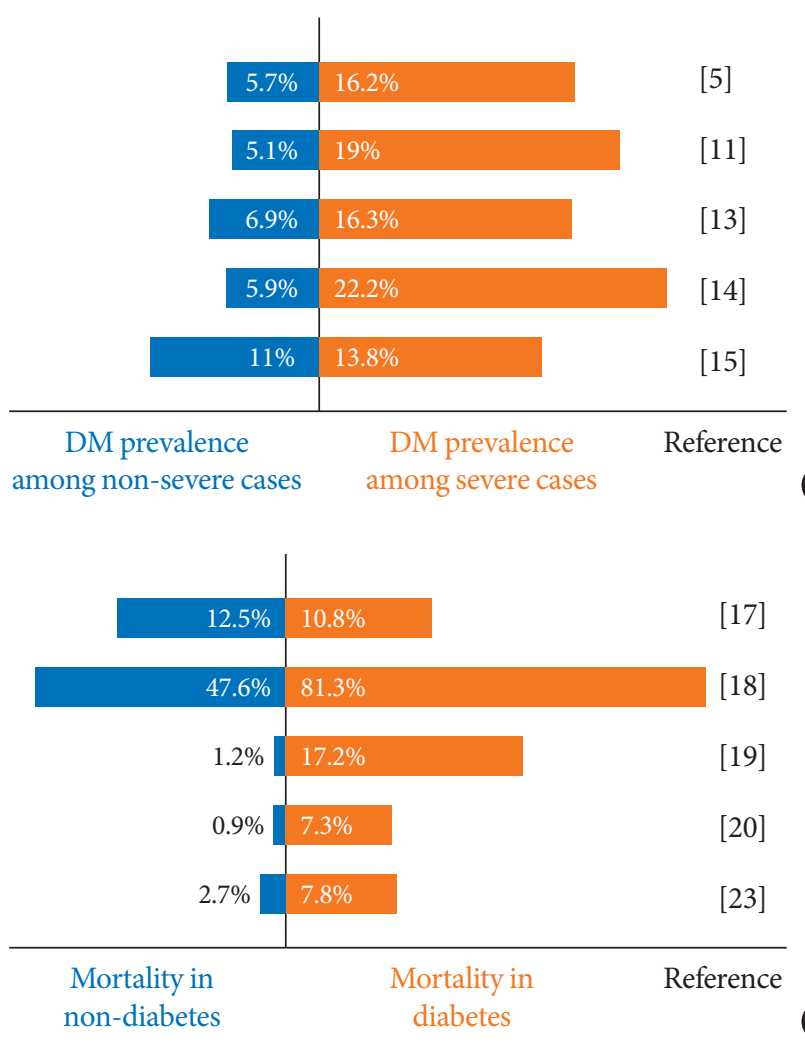

poorly controlled blood glucose (adjusted HR, 0.14) during hospitalization after adjusting for age, sex, COVID-19 severity, comorbidities, and side effects in patients with COVID-19 and pre-existing type 2 diabetes mellitus [23]. A single center study from Italy reported that the group treated with insulin infusion had better glycemic control and less severe COVID-19 [25]. These findings provide clinical evidence that uncontrolled hy-

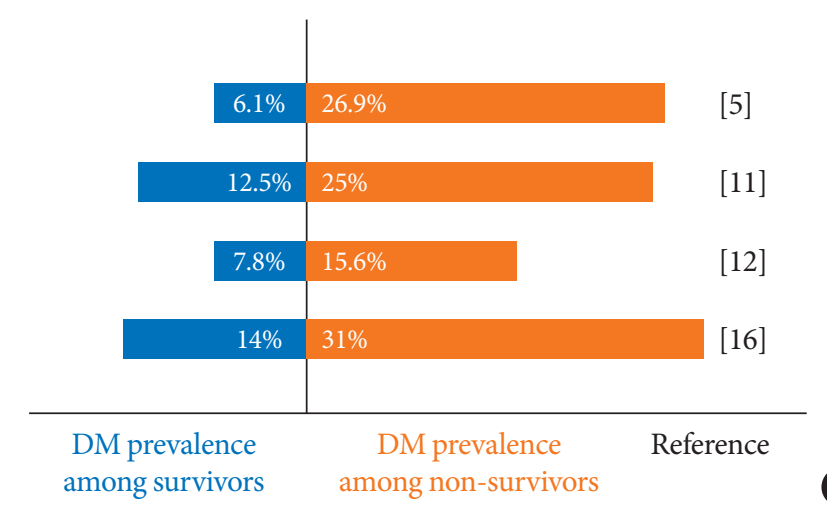

Fig. 1. Outcomes of coronavirus disease 2019 (COVID-19) in patients with diabetes. Diabetes prevalence among (A) all COVID-19 patients, (B) non-severe cases and severe cases, and (C) survivors and non-survivors. (D) Mortality in patients with and without diabetes. DM, diabetes mellitus.

perglycemia during hospitalization is associated with poor outcomes in COVID-19 patients with diabetes. Prospective controlled studies are needed to clarify the effect of hyperglycemia on the prognosis of COVID-19.

Diabetes might be associated with immune system impairment and may affect the inflammatory response to pathogens. Poorly controlled diabetes is linked to inhibited lymphocyte 


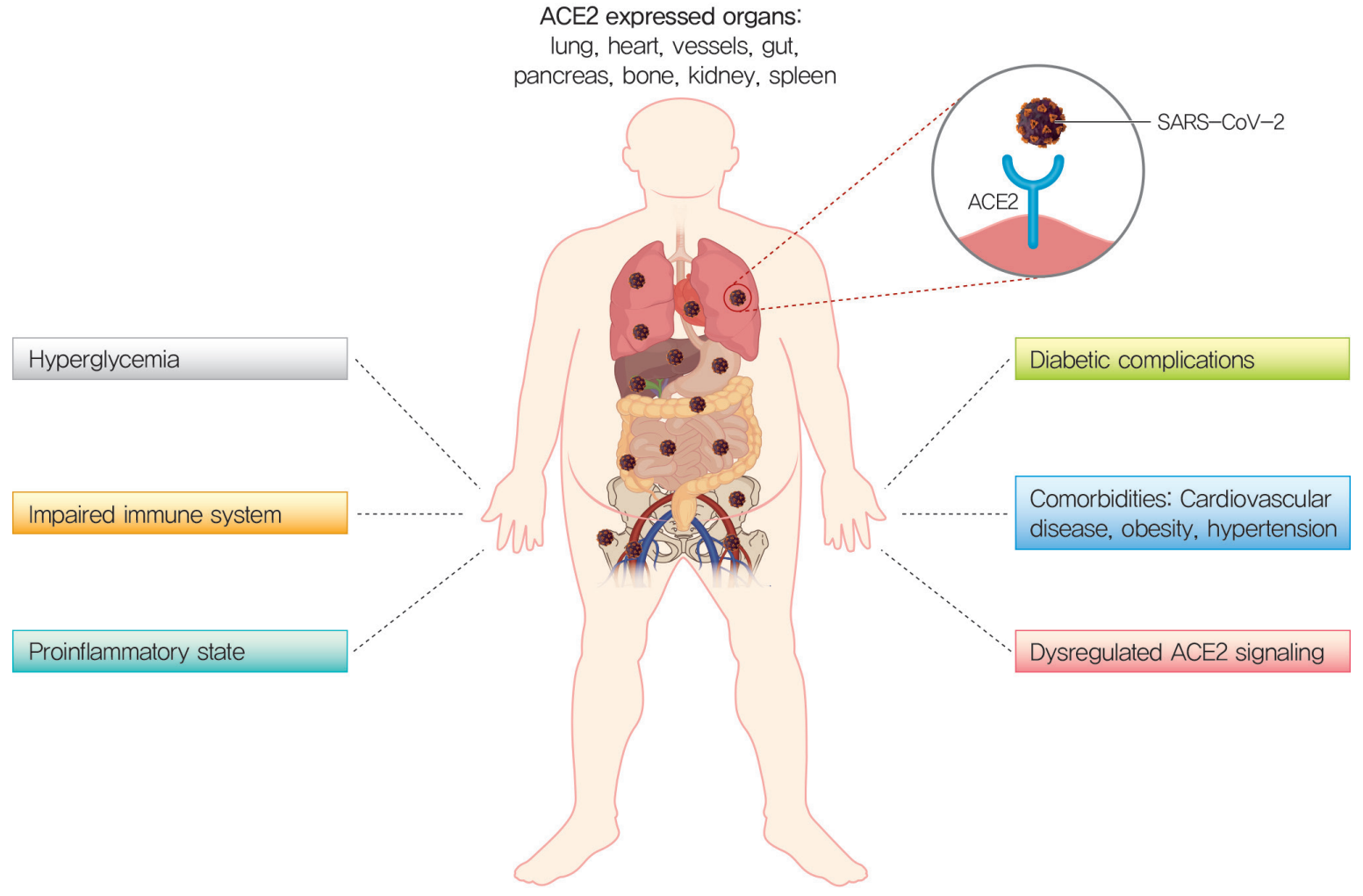

Fig. 2. The potential mechanisms linking diabetes and coronavirus disease 2019 (COVID-19). There are several suggested mechanisms that might play a role in an association between diabetes and COVID-19. Uncontrolled hyperglycemia, impaired immune system, pre-existing proinflammatory state, diabetic complications, multiple comorbidities, dysregulated state of angiotensinconverting enzyme 2 (ACE2) signaling. SARS-CoV-2, severe acute respiratory syndrome coronavirus-2.

proliferative responses to different stimuli [26], and impaired macrophage and neutrophil functions [27]. Furthermore, bactericidal activity following stimulation is decreased and bacterial phagocytosis and killing mechanisms are reduced in diabetic patients [28]. It was demonstrated that the respiratory burst of monocytes in patients with poorly controlled disease with hyperglycemia was severely impaired when compared to that in patients with well-controlled disease and healthy people [29]. Influenza virus infection and replication were significantly increased when pulmonary epithelial cells were exposed to high glucose concentrations [30].

Low-grade chronic inflammation is a common feature in subjects with type 2 diabetes mellitus. C-reactive protein (CRP), a well-established marker of the development of inflammation, tumor necrosis factor $\alpha$, an inflammatory marker, and interleukin 6 are strongly associated with diabetes [31]. Cytokines play a key role in promoting atherosclerosis and, therefore, cardiovascular disease [32]. Interestingly, ARDS in patients with COVID-19 is driven by severe hypoxemia despite relatively well-preserved lung mechanics [33]. A pre-existing proinflammatory state could accentuate the hyper-inflammatory response (cytokine storm), which is believed to be responsible for ARDS as well as multi-organ dysfunction in COVID-19 [34].

Comorbidities of diabetes might cause more susceptibility of COVID-19 in diabetic patients. Common demographics and comorbidities of diabetes such as older age, male sex, cardiovascular disease, hypertension, and obesity have been associated with poor outcomes in COVID-19 [11,35]. A retrospective single-center study conducted in Korea reported that age was an independent risk factor for severe outcomes in patients with diabetes [19]. In a study assessing the prognostic value of clinical and biological features, age, microvascular and macrovascular diabetic complications, treated obstructive sleep apnea, dyspnea, increased aspartate transaminase and CRP, and decreased estimated glomerular filtration rate and platelet count 
were independently associated with the risk of early death in patients with diabetes hospitalized for COVID-19 [24]. Obesity is also known as an independent risk factor of severity in COVID-19 patients [36].

Angiotensin-converting enzyme 2 (ACE2) protein, which is an important element in the regulation of blood pressure, metabolism, and inflammation, was also identified as the receptor for the coronavirus spike protein. SARS-CoV-2 enters the cell by binding to ACE2 [37]. There is experimental evidence for the downregulation of ACE2 in diabetes [38], which might reduce the entry of the virus into cells. Furthermore, ACE2 is expressed in pancreatic beta cells, SARS-CoV-2 might enter islets cells and cause beta-cell dysfunction [39]. On the other hand, ACE2 has been suggested to have a protective effect against inflammation-induced damage. Ang-(1-7) formed from AngII by ACE2 exerts inhibitory effects on inflammation and on vascular and cellular growth mechanisms by acting via the Mas receptor [40]. Downregulation of ACE2 in diabetes might make cells vulnerable to inflammation following viral infection.

Dipeptidyl peptidase-4 (DPP-4) inhibitors are one of the most frequently used medications in patients with type 2 diabetes mellitus. From in vitro experiments, DPP-4 was identified as a functional receptor for MERS-CoV for its entry into the cell [41]. Antibodies directed against DPP-4 inhibited MERS-CoV infection of primary cells [42]. DPP-4 may also have a role as an entry route for SARS-CoV-2, although it is not proven yet. In vitro treatment of DPP-4 inhibitors did not block the entry of coronavirus into cells [42]. On the other hand, the DPP-4 enzyme is known to be involved in the immune system and increases inflammation in type 2 diabetes mellitus [43]. Whether the DPP-4 enzyme also plays a role in the association between diabetes and COVID-19 is currently unknown.

\section{MANAGEMENT OF DIABETES IN COVID-19 PATIENTS}

\section{Management of hyperglycemia in COVID-19 patients with diabetes}

Based on mounting evidence supporting the effect of proper glycemic control on the prognosis of COVID-19, intensified glycemic control is recommended in COVID-19 patients with diabetes. Infection with SARS-CoV-2 might trigger stress conditions and increased secretion of stress hormones, such as cortisol and catecholamines, which result in the elevation of blood glucose and extreme glycemic excursion. In practice, cases of acute hyperglycemic crisis were reported in COVID-19 patients with diabetes $[44,45]$. There was a case report of the successful management of high-risk patients with type 1 diabetes mellitus and diabetic ketoacidosis using telehealth [46]. It is thought that during the pandemic, when health providers or diabetic patients are required to minimize contact and may even be quarantined, telehealth could provide alternative support in preventing acute complications and controlling sever hyperglycemia. People with diabetes who are not infected with the SARS-CoV-2 are also recommended to maintain optimal glycemic control as part of the primary prevention of COVID-19. COVID-19 patients without diabetes need to be monitored for new onset diabetes. Viral infection can trigger the onset of diabetes, and 28\% of COVID-19 patients with hyperglycemia had not been diagnosed as having diabetes before hospitalization in a single center study [25]. Also, during COVID-19 pandemic, social distancing, decrease of attendances to hospital facilities, limited access for patients, and remote consultations are easy to miss the urgent situations of diabetic complications such as diabetic foot, acute coronary syndrome, severe diabetic retinopathy, and so on. Therefore, doctors, healthcare providers, and patients need to be alert with regards to development and deterioration of diabetic complications.

\section{Special considerations for anti-diabetic medication in COVID-19 patients with diabetes}

Metformin is recommended as the first-line treatment of choice and one of the most frequently prescribed medications for type 2 diabetes mellitus. Metformin is contraindicated in people with concomitant sepsis or severe impairment of hepatic and renal function. As COVID-19 patients are vulnerable to dehydration and multi-organ failure, patients should follow the sick day rule and metformin should be stopped if severe renal or hepatic dysfunction is confirmed. Careful monitoring of renal function is needed during illness. Euglycemic ketoacidosis is rarely reported in type 2 diabetes mellitus treated with a sodium-glucose cotransporter-2 (SGLT-2) inhibitor. SGLT2 inhibitors should be discontinued for patients with renal dysfunction or severe SARS-CoV-2 infection who are dehydrated and have a risk of ketoacidosis. However, prophylactic discontinuation of these medications is not recommended for patients with mild symptoms or without any symptoms/organ failure. As previously described, a DPP-4 inhibitor was sug- 
gested to have a protective role against MERS [42]. There is a lack of evidence of SARS-CoV2 binding to DPP-4. DPP-4 inhibitors and glucagon-like peptide-1 receptor agonists may exert anti-inflammatory actions in human subjects and have been successfully used to control glucose levels in hospitalized patients [43]. A study using Korean national insurance claim data, analyzed 832 confirmed COVID-19 subjects with DM and, showed that use of a DPP-4 inhibitor is associated with better clinical outcomes in patients with COVID-19 [47]. However, whether DPP-4 inhibitors influence the course of the COVID-19 remains unclear. Insufficient secretion of insulin as a result of beta cell dysfunction can develop in patients with multiple stresses triggered by COVID-19. For intensive glucose control, the use of insulin is feasible. Treatment with insulin infusion showed better glycemic control and less severe COVID-19 in a retrospective study [25]. Because of the possibility of extreme blood excursion in patients with severe COVID-19, the risk of hypoglycemia should be carefully monitored with insulin use. Good glycemic control is important in improving the outcomes of patients with COVID-19. Anti-diabetic medications that effectively control blood glucose should have a beneficial effect on COVID-19 prognosis. Some antidiabetic medications are suggested to have immune-modulating effects expected to have additional benefits, but neither of them has been proven yet. Larger cohort studies are needed to prove specific anti-diabetic medication is beneficial independent of glycemic control in COVID-19 patients.

\section{Renin-angiotensin aldosterone system inhibitors}

Regarding the association between COVID-19 and ACE2, an increased risk of SARS-CoV-2 infection due to elevated expression of ACE2 in patients treated with ACE inhibitors or angiotensin II receptor blockers (ARBs) has been hypothesized. There is controversy over whether renin-angiotensin aldosterone system (RAAS) inhibitors are harmful or protective with respect to COVID-19. A positive test for COVID-19 or in the risk of severe COVID-19 were not increased in who patients take RAAS inhibitors [48]. A retrospective single-center study conducted in Korea also showed that use of ARB or ACE inhibitor medications was not associated with a critical outcome, but showed protective effects against acute cardiac injury (odds ratio [OR], 0.048; $P=0.05$ ) in diabetic patients with COVID-19 [19]. A study from Korea using national insurance claim data also showed no effect of RAAS blockade on clinical outcomes in COVID-19 in patients with diabetes [47]. In a meta-analysis of 12 studies involving more than 19,000 COVID-19 cases, RAAS inhibitor exposure was not associated with a higher risk of COVID-19. Among those with COVID-19 in-

Table 1. Korean Diabetes Association coronavirus disease 2019 prevention guideline for patients with diabetes

\begin{tabular}{ll}
\hline General health practice & Refrain from going out or visiting crowded areas. \\
& Make sure to wash your hands and keep cough etiquette. \\
& Do not touch your eyes, nose, and mouth with unwashed hands. \\
& Put on a mask before you visit a medical institution, avoid crowds, and avoid contacting someone with fever or \\
& respiratory symptoms. \\
Avoid personal contact at home as much as possible and always wipe the table, doorknob, and keyboard \\
frequently touched. \\
Make sure to keep oral medication and insulin administration more strict than usual. \\
Conduct and check self-monitoring of blood sugar more frequently. Once after waking up in the morning, once \\
2 hours after meals, that is conduct self-monitoring of blood sugar at least twice a day. If the result is \\
consistently higher than usual, visit your doctor or use the phone helpline. \\
Limanagement sugar for eating, have three meals, and balance your diets. Eat enough vegetables and take enough protein \\
as well. \\
Drink plenty of water to prevent infection. \\
Exercise is necessary in order to maintain immunity. Do a certain amount (minimum 30 minutes) of aerobic \\
exercises regularly every day at home. Do resistance exercise twice a week. \\
Contact the community healthcare center for such symptoms as a cough, phlegm, and a fever. Contact the \\
doctor for sudden blood sugar increase. If it is difficult to visit the doctor, consult through the phone helpline \\
allowed temporarily.
\end{tabular}


fection, RAAS inhibitor exposure was also not associated with a higher risk of severe outcomes or mortality. On the contrary, RAAS inhibitor exposure was associated with a lower risk of mortality compared to those on non-RAAS inhibitor antihypertensive drugs (OR, 0.48; 95\% confidence interval [CI], 0.29 to $0.81 ; P=0.006$ ) [49]. It is strongly recommended that patients who are taking ACE inhibitors or ARBs should not withdraw their current treatment regimens because of COVID-19.

\section{THE KDA'S SUGGESTIONS FOR COVID-19}

As there is the possibility for patients with diabetes, a typically immunosuppressive condition, to develop serious COVID-19, the KDA would like to make some official suggestions regarding the COVID-19 epidemiological emergency.

The KDA suggests that patients with diabetes, particularly, those over 70 years old, should have the opportunity to be tested and hospitalized when symptoms are first detected. In this situation, when nationwide spread is already suspected beyond local infection, preferential screening and hospitalization of high risk groups such as elderly patients with diabetes, who can progress to a serious condition will decrease the entire death toll and the number of deaths in the aged older population. This should prevent the development of serious illness, which would be an efficient response to COVID-19.

The KDA also provides COVID-19 prevention guidelines for patients with diabetes (Table 1). People with diabetes and health providers should be aware that they are more likely to develop serious illness than otherwise healthy people and follow strict prevention guidelines. In particular, patients with diabetes aged over 70 years are a high-risk group and require special care. The more difficult the situation is, the more important it is to measure blood sugar closely and strictly maintain life style. The KDA suggests refraining from going out or visiting crowded areas, ensuring good hand washing, maintaining cough etiquette, avoiding touching the face with unwashed hands, putting on a mask before visiting a medical institution, and avoiding contacting someone with fever or respiratory symptoms. The KDA also recommends avoiding personal contact at home as much as possible and always wiping frequently touched surfaces such as tables, doorknob, and keyboard. For blood sugar management, the KDA suggests taking oral medications and administering insulin more strictly than usual, and self-monitoring blood sugar more frequently. Selfmonitoring of blood sugar should be performed at least twice a day (after waking up in the morning and once 2 hours after meals). If the result is consistently higher than usual, patients should visit their doctor or use the phone helpline. Proper nutrition therapy is also important. Sugar consumption should be limited. Regular three meals and balanced diet are essential. Sufficient vegetable and protein consumption is also recommended. The KDA also recommends drinking plenty of water to prevent infection. Exercise is necessary in order to maintain immunity. A certain amount (minimum 30 minutes) of regular aerobic exercise is recommended every day at home. Regular resistance exercises are also recommended at least twice a week. Contacting the community healthcare center is needed if there are any symptoms such as a cough, phlegm, or fever. Immediate contact with a doctor is also needed when blood sugar levels reveal a sudden and consistent increase. If it is difficult to visit a doctor, consult through the phone helpline allowed temporarily.

\section{CONCLUSIONS}

Close attention and timely adequate care are essential for the prevention and proper treatment of COVID-19 in diabetic patients. Expanding our knowledge about COVID-19, developing medications for SARS-CoV-2 infection, and conducting studies for identifying unanswered questions about the pathogenic pathway, risk factors, and effects of anti-diabetic medications on COVID-19 outcomes and the best practice for managing diabetes during pandemic are essential. For the future another infectious disease pandemic, we have to prepare nationwide remote monitoring and couching system for diabetic patients as soon as possible. The KDA will spare no effort in closely cooperating with health authorities for patients with diabetes to overcome the current difficulties related to COVID-19.

\section{CONFLICTS OF INTEREST}

No potential conflict of interest relevant to this article was reported.

\section{ORCID}

Junghyun Noh https://orcid.org/0000-0002-7964-0515

In-Kyung Jeong https://orcid.org/0000-0001-7857-546X

Kun Ho Yoon https://orcid.org/0000-0002-9109-2208 


\section{ACKNOWLEDGMENTS}

This research did not receive any specific grant from funding agencies in the public, commercial, or not-for-profit sectors.

We want to thank the support of the members of board of directors of Korean Diabetes Associations: Hak Chul Jang (President of KDA), Kun Ho Yoon (Chairman, Board of Directors), Yeon-Ah Sung, Minho Shong, Cheol Soo Choi, Kang Hee Sim, Sei Hyun Baik, Young Sik Choi, Sung Rae Kim, Kyu Chang Won, Sang Yong Kim, Hyuk Sang Kwon, Won Young Lee, Kee Ho Song, Chong Hwa Kim, Seungjoon Oh, SeungHyun Ko, Jaehyeon Kim, Eun Seok Kang, Seak Ki Yun, Young Min Cho, Nan Hee Kim, Chang Beom Lee, Sin Gon Kim, Sung-Woo Ha, Bon Jeong Ku, Cheol-Young Park, You-Cheol Hwang, Eun Jung Rhee, So Hun Kim, Seung-Hwan Lee, Jang Won Son, Sang Soo Kim, Bo Kyung Koo, Jung Hwan Park, Chang-Hee Jung. We especially thank the Ji Oh Mok (Director, Committee of Media-Public Relation) and Sung Hee Choi (Director, Committee of International Liaison).

\section{REFERENCES}

1. World Health Organization: Coronavirus disease 2019 (COVID-19) situation report 109. Available from: https://www.who. int/emergencies/diseases/novel-coronavirus-2019 (cited 2020 Jun 22).

2. Korean Ministry of Health and Welfare: Cases in Korea. Available from: http://ncov.mohw.go.kr/en/bdBoardList.do?brdId= 16\&brdGubun $=161 \&$ dataGubun $=\&$ ncvContSeq $=\&$ contSeq $=$ \&board_id= (cited 2020 Jun 22).

3. Peeri NC, Shrestha N, Rahman MS, Zaki R, Tan Z, Bibi S, Baghbanzadeh M, Aghamohammadi N, Zhang W, Haque U. The SARS, MERS and novel coronavirus (COVID-19) epidemics, the newest and biggest global health threats: what lessons have we learned? Int J Epidemio $2020 \mathrm{Feb} 22$ [Epub]. https://doi.org/10.1093/ije/dyaa033.

4. Yang X, Yu Y, Xu J, Shu H, Xia J, Liu H, Wu Y, Zhang L, Yu Z, Fang M, Yu T, Wang Y, Pan S, Zou X, Yuan S, Shang Y. Clinical course and outcomes of critically ill patients with SARS-CoV-2 pneumonia in Wuhan, China: a single-centered, retrospective, observational study. Lancet Respir Med 2020;8:475-81.

5. Guan WJ, Ni ZY, Hu Y, Liang WH, Ou CQ, He JX, Liu L, Shan H, Lei CL, Hui DSC, Du B, Li LJ, Zeng G, Yuen KY, Chen RC, Tang CL, Wang T, Chen PY, Xiang J, Li SY, Wang JL, Liang ZJ, Peng YX, Wei L, Liu Y, Hu YH, Peng P, Wang JM, Liu JY, Chen
Z, Li G, Zheng ZJ, Qiu SQ, Luo J, Ye CJ, Zhu SY, Zhong NS; China Medical Treatment Expert Group for Covid-19. Clinical characteristics of coronavirus disease 2019 in China. N Engl J Med 2020;382:1708-20.

6. COVID-19 National Emergency Response Center, Epidemiology and Case Management Team, Korea Centers for Disease Control and Prevention. Coronavirus disease-19: the first 7,755 cases in the Republic of Korea. Osong Public Health Res Perspect 2020;11:85-90.

7. Huang I, Lim MA, Pranata R. Diabetes mellitus is associated with increased mortality and severity of disease in COVID-19 pneumonia: a systematic review, meta-analysis, and meta-regression. Diabetes Metab Syndr 2020;14:395-403.

8. Carey IM, Critchley JA, DeWilde S, Harris T, Hosking FJ, Cook DG. Risk of infection in type 1 and type 2 diabetes compared with the general population: a matched cohort study. Diabetes Care 2018;41:513-21.

9. Schoen K, Horvat N, Guerreiro NFC, de Castro I, de Giassi KS. Spectrum of clinical and radiographic findings in patients with diagnosis of H1N1 and correlation with clinical severity. BMC Infect Dis 2019;19:964.

10. Song Z, Xu Y, Bao L, Zhang L, Yu P, Qu Y, Zhu H, Zhao W, Han Y, Qin C. From SARS to MERS, thrusting coronaviruses into the spotlight. Viruses 2019;11:59.

11. Wu C, Chen X, Cai Y, Xia J, Zhou X, Xu S, Huang H, Zhang L, Zhou X, Du C, Zhang Y, Song J, Wang S, Chao Y, Yang Z, Xu J, Zhou X, Chen D, Xiong W, Xu L, Zhou F, Jiang J, Bai C, Zheng J, Song Y. Risk factors associated with acute respiratory distress syndrome and death in patients with coronavirus disease 2019 pneumonia in Wuhan, China. JAMA Intern Med 2020 Mar 13 [Epub]. https://doi.org/10.1001/jamainternmed.2020.0994.

12. Deng Y, Liu W, Liu K, Fang YY, Shang J, Zhou L, Wang K, Leng F, Wei S, Chen L, Liu HG. Clinical characteristics of fatal and recovered cases of coronavirus disease 2019 in Wuhan, China: a retrospective study. Chin Med J (Engl) 2020;133:1261-7.

13. Chen Q, Zheng Z, Zhang C, Zhang X, Wu H, Wang J, Wang S, Zheng C. Clinical characteristics of 145 patients with corona virus disease 2019 (COVID-19) in Taizhou, Zhejiang, China. Infection 2020 Apr 28 [Epub]. https://doi.org/10.1007/s15010020-01432-5.

14. Wang D, Hu B, Hu C, Zhu F, Liu X, Zhang J, Wang B, Xiang H, Cheng Z, Xiong Y, Zhao Y, Li Y, Wang X, Peng Z. Clinical characteristics of 138 hospitalized patients with 2019 novel coronavirus-infected pneumonia in Wuhan, China. JAMA 2020;323: 1061-9. 
15. Zhang JJ, Dong X, Cao YY, Yuan YD, Yang YB, Yan YQ, Akdis CA, Gao YD. Clinical characteristics of 140 patients infected with SARS-CoV-2 in Wuhan, China. Allergy 2020 Feb 19 [Epub]. https://doi.org/10.1111/all.14238.

16. Zhou F, Yu T, Du R, Fan G, Liu Y, Liu Z, Xiang J, Wang Y, Song B, Gu X, Guan L, Wei Y, Li H, Wu X, Xu J, Tu S, Zhang Y, Chen $\mathrm{H}$, Cao B. Clinical course and risk factors for mortality of adult inpatients with COVID-19 in Wuhan, China: a retrospective cohort study. Lancet 2020;395:1054-62.

17. Guo W, Li M, Dong Y, Zhou H, Zhang Z, Tian C, Qin R, Wang H, Shen Y, Du K, Zhao L, Fan H, Luo S, Hu D. Diabetes is a risk factor for the progression and prognosis of COVID-19. Diabetes Metab Res Rev 2020 Mar 31 [Epub]. https://doi.org/10.1002/ dmrr.3319.

18. Yan Y, Yang Y, Wang F, Ren H, Zhang S, Shi X, Yu X, Dong K. Clinical characteristics and outcomes of patients with severe COVID-19 with diabetes. BMJ Open Diabetes Res Care 2020; 8:e001343.

19. Chung SM, Lee YY, Ha E, Yoon JS, Won KC, Lee HW, Hur J, Hong KS, Jang JG, Jin HJ, Choi EY, Shin KC, Chung JH, Lee $\mathrm{KH}, \mathrm{Ahn} \mathrm{JH}$, Moon JS. The risk of diabetes on clinical outcomes in patients with coronavirus disease 2019: a retrospective cohort study. Diabetes Metab J 2020;44:405-13.

20. The Novel Coronavirus Pneumonia Emergency Response Epidemiology Team. Vital surveillances: the epidemiological characteristics of an outbreak of 2019 novel coronavirus diseases (COVID-19): China, 2020. China CDC Wkly 2020;2:113-22.

21. CDC COVID-19 Response Team. Preliminary estimates of the prevalence of selected underlying health conditions among patients with coronavirus disease 2019: United States, February 12-March 28, 2020. MMWR Morb Mortal Wkly Rep 2020;69: 382-6.

22. Shi Q, Zhang X, Jiang F, Zhang X, Hu N, Bimu C, Feng J, Yan S, Guan Y, Xu D, He G, Chen C, Xiong X, Liu L, Li H, Tao J, Peng Z, Wang W. Clinical characteristics and risk factors for mortality of COVID-19 patients with diabetes in Wuhan, China: a two-center, retrospective study. Diabetes Care 2020 May 14 [Epub]. https://doi.org/10.2337/dc20-0598.

23. Zhu L, She ZG, Cheng X, Qin JJ, Zhang XJ, Cai J, Lei F, Wang H, Xie J, Wang W, Li H, Zhang P, Song X, Chen X, Xiang M, Zhang C, Bai L, Xiang D, Chen MM, Liu Y, Yan Y, Liu M, Mao W, Zou J, Liu L, Chen G, Luo P, Xiao B, Zhang C, Zhang Z, Lu Z, Wang J, Lu H, Xia X, Wang D, Liao X, Peng G, Ye P, Yang J, Yuan Y, Huang X, Guo J, Zhang BH, Li H. Association of blood glucose control and outcomes in patients with COVID-19 and pre-existing type 2 diabetes. Cell Metab 2020;31:1068-77.

24. Cariou B, Hadjadj S, Wargny M, Pichelin M, Al-Salameh A, Allix I, Amadou C, Arnault G, Baudoux F, Bauduceau B, Borot S, Bourgeon-Ghittori M, Bourron O, Boutoille D, CazenaveRoblot F, Chaumeil C, Cosson E, Coudol S, Darmon P, Disse E, Ducet-Boiffard A, Gaborit B, Joubert M, Kerlan V, Laviolle B, Marchand L, Meyer L, Potier L, Prevost G, Riveline JP, Robert R, Saulnier PJ, Sultan A, Thebaut JF, Thivolet C, Tramunt B, Vatier C, Roussel R, Gautier JF, Gourdy P; CORONADO investigators. Phenotypic characteristics and prognosis of inpatients with COVID-19 and diabetes: the CORONADO study. Diabetologia 2020 May 29 [Epub]. https://doi.org/10.1007/ s00125-020-05180-x.

25. Sardu C, D’Onofrio N, Balestrieri ML, Barbieri M, Rizzo MR, Messina V, Maggi P, Coppola N, Paolisso G, Marfella R. Outcomes in patients with hyperglycemia affected by COVID-19: can we do more on glycemic control? Diabetes Care 2020 May 19 [Epub]. https://doi.org/10.2337/dc20-0723.

26. Moutschen MP, Scheen AJ, Lefebvre PJ. Impaired immune responses in diabetes mellitus: analysis of the factors and mechanisms involved. Relevance to the increased susceptibility of diabetic patients to specific infections. Diabete Metab 1992;18: 187-201.

27. Knapp S. Diabetes and infection: is there a link? A mini-review. Gerontology 2013;59:99-104.

28. Delamaire M, Maugendre D, Moreno M, Le Goff MC, Allannic $\mathrm{H}$, Genetet B. Impaired leucocyte functions in diabetic patients. Diabet Med 1997;14:29-34.

29. Chang FY, Shaio MF. Respiratory burst activity of monocytes from patients with non-insulin-dependent diabetes mellitus. Diabetes Res Clin Pract 1995;29:121-7.

30. Kohio HP, Adamson AL. Glycolytic control of vacuolar-type ATPase activity: a mechanism to regulate influenza viral infection. Virology 2013;444:301-9.

31. Bastard JP, Jardel C, Bruckert E, Vidal H, Hainque B. Variations in plasma soluble tumour necrosis factor receptors after dietinduced weight loss in obesity. Diabetes Obes Metab 2000;2: 323-5.

32. Ross R. Atherosclerosis: an inflammatory disease. N Engl J Med 1999;340:115-26.

33. Gattinoni L, Coppola S, Cressoni M, Busana M, Rossi S, Chiumello D. COVID-19 does not lead to a "typical" acute respiratory distress syndrome. Am J Respir Crit Care Med 2020;201: 1299-300.

34. Maddaloni E, Buzzetti R. Covid-19 and diabetes mellitus: un- 
veiling the interaction of two pandemics. Diabetes Metab Res Rev 2020 Mar 31 [Epub]. https://doi.org/10.1002/dmrr.3321.

35. Zheng Z, Peng F, Xu B, Zhao J, Liu H, Peng J, Li Q, Jiang C, Zhou Y, Liu S, Ye C, Zhang P, Xing Y, Guo H, Tang W. Risk factors of critical \& mortal COVID-19 cases: a systematic literature review and meta-analysis. J Infect 2020 Apr 23 [Epub]. https://doi.org/10.1016/j.jinf.2020.04.021.

36. Cai Q, Chen F, Wang T, Luo F, Liu X, Wu Q, He Q, Wang Z, Liu Y, Liu L, Chen J, Xu L. Obesity and COVID-19 severity in a designated hospital in Shenzhen, China. Diabetes Care 2020 May 14 [Epub]. https://doi.org/10.2337/dc20-0576.

37. Hoffmann M, Kleine-Weber H, Schroeder S, Kruger N, Herrler T, Erichsen S, Schiergens TS, Herrler G, Wu NH, Nitsche A, Muller MA, Drosten C, Pohlmann S. SARS-CoV-2 cell entry depends on ACE2 and TMPRSS2 and is blocked by a clinically proven protease inhibitor. Cell 2020;181:271-80.

38. Li XC, Zhang J, Zhuo JL. The vasoprotective axes of the reninangiotensin system: physiological relevance and therapeutic implications in cardiovascular, hypertensive and kidney diseases. Pharmacol Res 2017;125(Pt A):21-38.

39. Yang JK, Lin SS, Ji XJ, Guo LM. Binding of SARS coronavirus to its receptor damages islets and causes acute diabetes. Acta Diabetol 2010;47:193-9.

40. Rodrigues Prestes TR, Rocha NP, Miranda AS, Teixeira AL, Simoes-E-Silva AC. The anti-inflammatory potential of ACE2/ angiotensin-(1-7)/mas receptor axis: evidence from basic and clinical research. Curr Drug Targets 2017;18:1301-13.

41. Arabi YM, Balkhy HH, Hayden FG, Bouchama A, Luke T, Baillie JK, Al-Omari A, Hajeer AH, Senga M, Denison MR, Nguyen-Van-Tam JS, Shindo N, Bermingham A, Chappell JD, Van Kerkhove MD, Fowler RA. Middle East respiratory syn- drome. N Engl J Med 2017;376:584-94.

42. Raj VS, Mou H, Smits SL, Dekkers DH, Muller MA, Dijkman R, Muth D, Demmers JA, Zaki A, Fouchier RA, Thiel V, Drosten C, Rottier PJ, Osterhaus AD, Bosch BJ, Haagmans BL. Dipeptidyl peptidase 4 is a functional receptor for the emerging human coronavirus-EMC. Nature 2013;495:251-4.

43. Drucker DJ. Coronavirus infections and type 2 diabetes-shared pathways with therapeutic implications. Endocr Rev 2020; 41:bnaa011.

44. Kim NY, Ha E, Moon JS, Lee YH, Choi EY. Acute hyperglycemic crises with coronavirus disease-19: case reports. Diabetes Metab J 2020;44:349-53.

45. Li J, Wang X, Chen J, Zuo X, Zhang H, Deng A. COVID-19 infection may cause ketosis and ketoacidosis. Diabetes Obes Metab 2020 Apr 20 [Epub]. https://doi.org/10.1111/dom.14057.

46. Garg SK, Rodbard D, Hirsch IB, Forlenza GP. Managing newonset type 1 diabetes during the COVID-19 pandemic: challenges and opportunities. Diabetes Technol Ther 2020;22:4319.

47. Rhee SY, Lee J, Nam H, Kyoung DS, Kim DJ. Effects of a DPP-4 inhibitor and RAS blockade on clinical outcomes of patients with diabetes and COVID-19. Medrxivpreprint. https://doi.or g/10.1101/2020.05.20.20108555.

48. Reynolds HR, Adhikari S, Pulgarin C, Troxel AB, Iturrate E, Johnson SB, Hausvater A, Newman JD, Berger JS, Bangalore S, Katz SD, Fishman GI, Kunichoff D, Chen Y, Ogedegbe G, Hochman JS. Renin-angiotensin-aldosterone system inhibitors and risk of COVID-19. N Engl J Med 2020;382:2441-8.

49. Zhang X, Yu J, Pan LY, Jiang HY. ACEI/ARB use and risk of infection or severity or mortality of COVID-19: A systematic review and meta-analysis. Pharmacol Res 2020;158:104927. 